\title{
Multidisciplinary Treatment of an Adult Patient with a High Esthetic Demand
}

Gözde ÇELIK, Simge TAŞIN, Sabri İlhan RAMOĞLU, Merve SUCU, Aslıhan ÜŞÜMEZ

Bezmialem Vakuf University, School of Dentistry, İstanbul, Turkey

\section{ABSTRACT}

Currently, esthetic expectations of the treatment of adult patients are increasing. However, these patients often present with serious oral problems, such as overcrowding, ageneses, edentulous spaces from old extractions, and periodontal problems. Considering all these problems, we require interdisciplinary strategies that will help us perform complex and imaginative treatments that are required. This case report describes the multidisciplinary treatment of a 40-year-old patient with anterior crossbite and missing teeth with an implantsupported fixed prosthesis.

Keywords: Multidisciplinary approach, crossbite, congenitally missing teeth, case report

\section{Introduction}

The esthetic expectations of adult patients after treatment are continually increasing (1). The loss of teeth or periodontal support in these patients may cause the pathologic migration of teeth, and as a result, anomalies in tooth position occur. When this condition is accompanied by skeletal incompatibilities, better results can be obtained in terms of esthetics and function via multidisciplinary approaches in which prosthetic or periodontal approaches are supported by orthodontic and surgical methods $(2,3)$.

The loss of periodontal support, particularly that accompanied by tooth loss, causes the pathologic migration of a single tooth or a group of teeth. This situation may result in incisor proclination or retrusion, tipping and rotation in premolars and molars, and a reduction in vertical dimension with posterior occlusion collapse (4).

The main objective of periodontal treatment is to treat the periodontal attachments of teeth and to maintain integrity. Treatment supported by orthodontics is necessary to facilitate the management of esthetic and restorative difficulties, depending on pathologic migration (4).

The aim of this case report was to present and discuss the results of periodontal, orthodontic, implant, and prosthetic dentistry teamwork to provide the ideal function and esthetics in the treatment of adult patients with missing teeth.

\section{Case Report}

A 40-year-old male applied to the Department of Prosthodontic Dentistry for the correction of the appearance of the upper front teeth and for replacement of missing teeth. In the intraoral and radiological evaluations that were performed, multiple toothless areas, periodontal problems, extended and cross-biting incisors, and agenesis of teeth \#12 and 22 were seen. The patient's upper jaw was Kennedy Class II, mod 3 and the lower jaw was Kennedy Class II, mod 1 (Figure 1).

Treatment options were explained to the patient. The patient was informed that orthodontic treatment before prosthetic treatment would provide better dental relations and esthetics. Following the mutual evaluation of the treatment options, an implant-supported fixed prosthesis was decided after orthodontic treatment. 

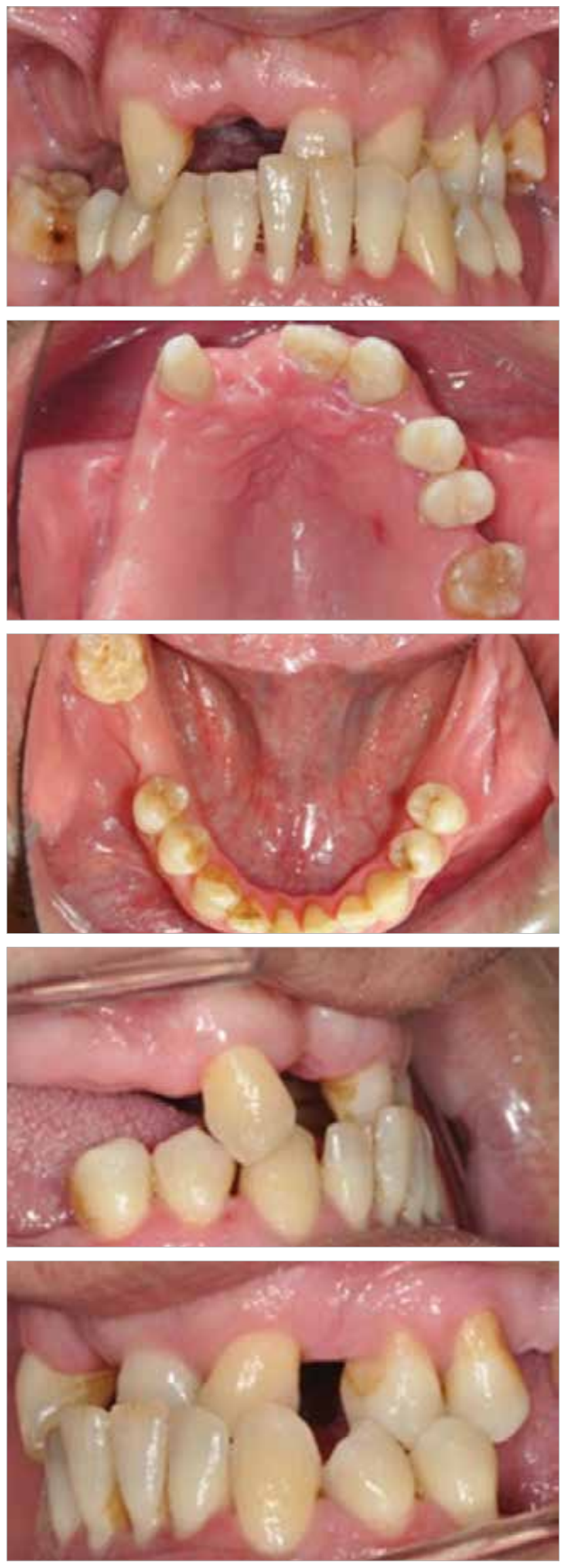

Figure 1. Intraoral frontal, maxillary, submaxillary, and right and left biting views of the patient before treatment
In the cephalometric evaluation of the patient, it was thought that retroclined upper incisors could be proclined. During the leveling and alignment of the lower anterior teeth, proclination of the upper incisors was also required for an acceptable overjet-overbite relationship as they would be protruding. It was predicted that the dark interproximal triangles would become more visible after leveling, depending on the periodontal losses and the shapes of the lower incisors. It was decided that enamoplasty should be performed by stripping the lower incisors and that the lower incisors should be retroclined as much as possible in order to reduce this problem and reduce the extent of upper incisor protrusion. In addition, it was decided to adjust the positions of the supporting teeth so that restorations could be proportional. In addition, the bite was opened to achieve an overbite of $1-2 \mathrm{~mm}$ in the central tooth to decrease the prominence of the jaw and increase the vertical dimension.

Scaling and root planning were performed by the periodontologist, and crown preparations were made for restoration in teeth \#13,21, 23, 24, and 25. Temporary dental restorations (Takilon, autopolymerizing resin, Italy) were prepared and cemented with permanent cement (Poly-F Plus, Dentsply). Three implants were placed in regions \#14, 16, and 36. In regions \#16 and 36, implants (Implant Ce, Trabzon, Turkey) with a diameter of $4.3 \mathrm{~mm}$ and length of $12 \mathrm{~mm}$ were used, and in region \#14, implants with a diameter of $4.8 \mathrm{~mm}$ and length of $12 \mathrm{~mm}$ were used. No graft application or similar advanced surgical procedure was performed during surgery. Orthodontic treatment was completed while the osteointegration process was under way. A Roth 18 slot metal bracket system was used. At the end of treatment, the lower anterior teeth were retained with a lingual retainer and the upper teeth with a transparent retainer (Figure 2). The patient was followed up at the newly determined vertical dimension until the start of prosthetic treatment, and no complaints were encountered.

Five months after the placement of implants, healing heads were placed, and measurements were taken after the oneweek gingival healing process. The occlusal and vertical associations of the patient were detected by occlusal bite recording. Subsequently, metal and porcelain rehearsals were made (Figure 3). An Angle Class I occlusion was provided in the sagittal direction between the jaws during fitting of the porcelain rehearsal, and the occlusion type was set to groupfunction occlusion. After the patient's approval in terms of esthetics and function was received, the restorations were cemented (Figure 4). Verbal and visual explanations were given to the patient on how to use, clean, and maintain his prostheses, and necessary instructions were given to him in written form. The patient was called in for tests after periods of 6 months, 1 year, and 2 years. The patient got used to his prostheses in a short time and developed speech and chewing functions during the follow-up period. In addition, the patient stated that his self-esteem and quality of life 

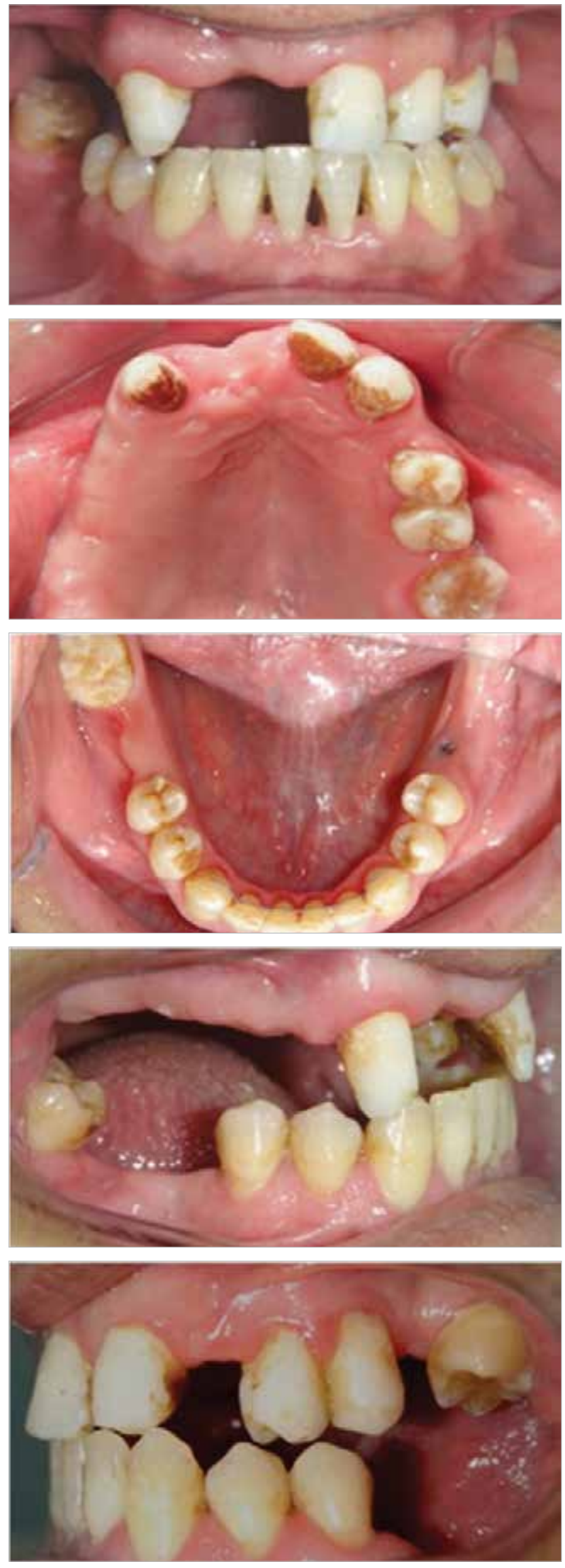

Figure 2. Intraoral frontal, maxillary, submaxillary, and right and left biting views of the patient after treatment

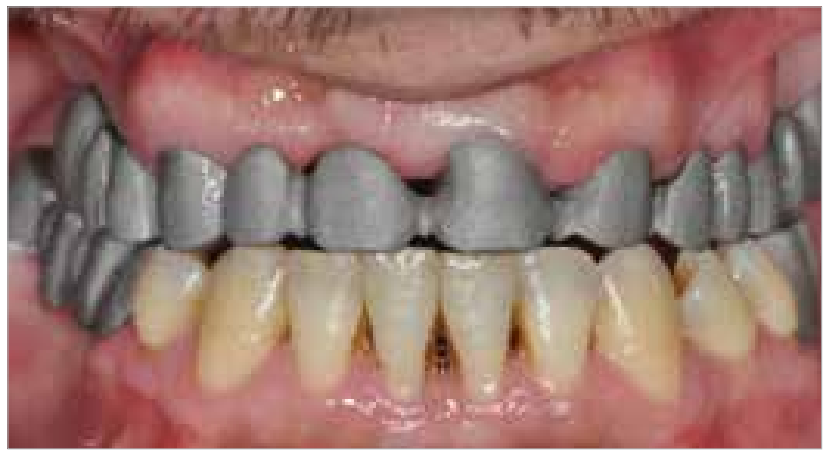

Figure 3. The rehearsal view of the metal infrastructure used in the patient

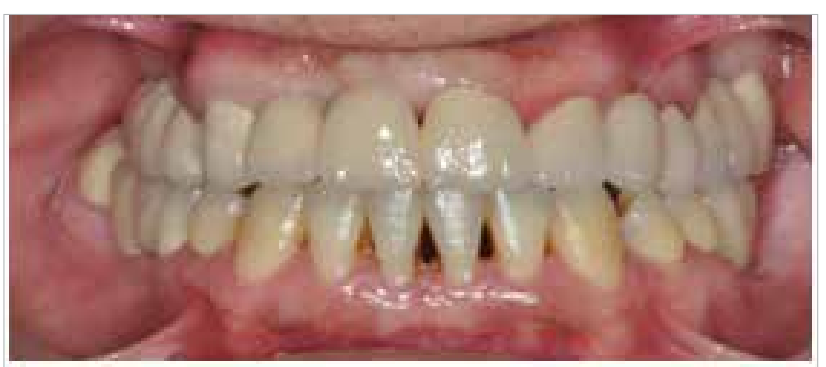

\section{Figure 4. End-of-treatment appearance of the patient}
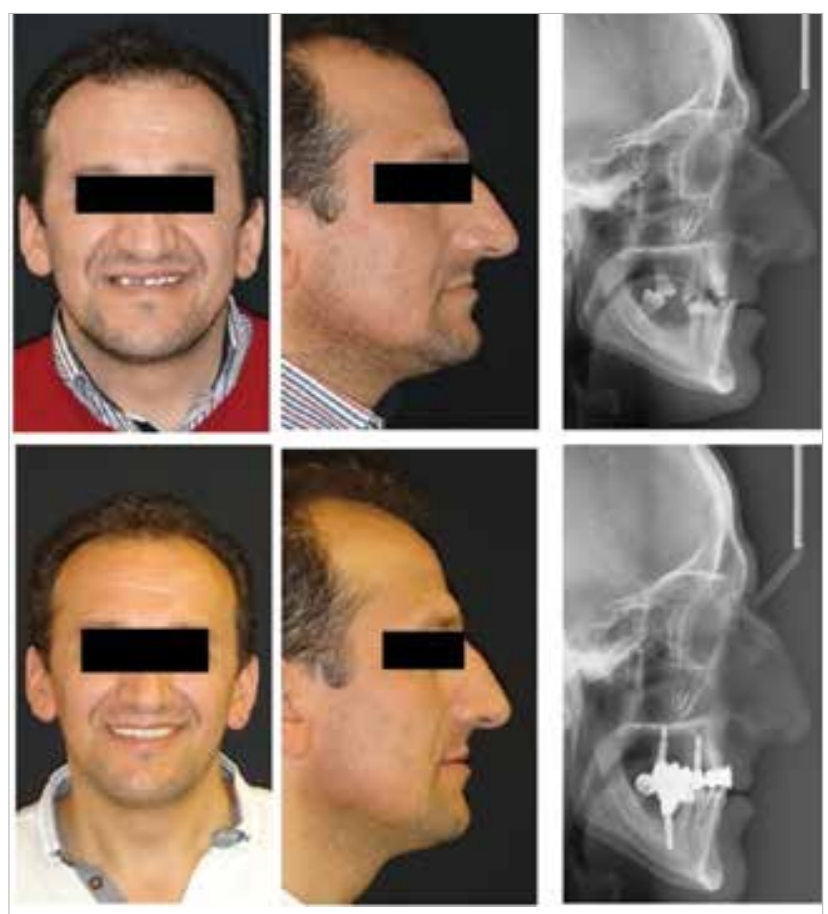

Figure 5. Pre- and post-treatment facial photographs and cephalometric radiographs

increased. After the tests, the patient's treatment was completed (Figure 5).

The patient was given detailed information about the treatment to be employed. His consent was received for using, publishing, and archiving of the films and photographs taken. 


\section{Discussion}

In particular, the rehabilitation of maxillary anterior tooth deficiencies is considered to be one of the most difficult treatments in dentistry owing to the esthetic concerns. If malocclusion is accompanied by dental deficiency, there is a requirement for orthodontic treatment to maintain the physiological health of the stomatognathic system for a long period before prosthetic treatment. Patients who refuse orthodontic treatment owing to both economic and temporal reasons can only be treated by a prosthetic approach (5). In this case, the abnormal positions of the teeth will prevent physiological cleansing of the teeth, as well as creating an etiological factor that causes periodontal breakdown by preparing the way for the formation of excessive occlusal forces (6).

An alternative treatment by a solely prosthetic approach comprises the application of a maxillary fixed prosthesis and a maxillary removable partial denture (RPD) that includes all the upper jaw teeth and the application of a mandibular RPD. RPDs are not comfortable and, in particular, the clasps on the front teeth can cause esthetic difficulties. They may cause damage and wear to the healthy teeth that they surround. The force applied to the teeth in cases of inadequate gingival health can cause a tooth to be lost. As a solution, the force exerted on a single tooth can be distributed by bridging teeth together. Preparing many healthy teeth for restoration with conventional fixed dentures will require highly invasive procedures.

The literature shows that implant-supported prostheses are successful in long-term use. The greatest advantage of implant-supported prostheses is that no procedure is performed on healthy adjacent teeth (7-9). Priest showed in a 10 -year clinical trial that there would be fewer cases of caries, less risk of orthodontic movements, less sensitivity, and less plaque retention in adjacent teeth with implant therapy (10). Prostheses built on an implant create a natural structure while replacing the missing teeth and the surrounding bone tissue is preserved.

If the treatment had not been supported by orthodontic methods in presented case, the amount of preparation in the maxillary teeth would have been increased in order to provide an ideal overjet and overbite and the teeth would have been more protruding. The preparation would have been required both to reduce the protrusion and to correct the difference in the level in the mandibular teeth. The increase in the amount of preparation could have caused periodontal and endodontic problems in the teeth, and the treatment would have become more complex. Because the teeth were not in their correct position, the dimensional proportions of the teeth with respect to each other could not have been prosthetically achieved.

\section{Conclusions}

In the light of the literature and considering the conditions, the patient was given a healthy and esthetic smile by aiming to preserve the neighboring teeth as well as the physiology of the stomatognathic system in a multidisciplinary approach.

Informed Consent: Informed consent was obtained from patients who participated in this study.

Peer-review: Externally peer-reviewed.

Author Contributions: Concept - G.Ç., S.T.; Design - S.T., S.İ.R.; Supervision - S.T., S.İ.R., A.Ü.; Data Collection and/or Processing - S.T., M.S.; Analysis and/or Interpretation - S.T., S.İ.R., A.Ü.; Literature Review - S.T.; Writing - S.T., S.İ.R., A.Ü.; Critical Review - S.T., S.İ.R., A.Ü.

Conflict of Interest: No conflict of interest was declared by the authors.

Financial Disclosure: The authors declared that this study has received no financial support.

\section{References}

1. Pinho T, Neves M, Alves C. Multidisciplinary management including periodontics, orthodontics, implants, and prosthetics for an adult. Am J Orthod Dentofacial Orthop 2012; 142: 235-45. [CrossRef]

2. Cronin RJ, Cagna DR. An update on fixed prosthodontics. J Am Dent Assoc 1997; 128: 425-36. [CrossRef]

3. Phillips K, Kois J. Aesthetic peri-implant site development. The restorative connection. Dent Clin North Am 1998; 42: 57-70.

4. Ong MA, Wang HL, Smith FN. Interrelationship between periodontics and adult orthodontics. J Clin Periodontol 1998; 25: 271-7. [CrossRef]

5. Misch CE. Üst çene ön bölgede tek diş eksikliği ve tedavisi. In: Kutay Ö, editor. Dental İmplant Protezler. İstanbul: Nobel Tip Kitapevleri; 2009.p.368-413.

6. Kessler M. İnterrelationship between orthodontics and periodontics. Am J Orthod 1976; 70: 154-72. [CrossRef]

7. Kokich VO, Kinzer GA, Janakievski J. Congenitally missing maxillary lateral incisors: restorative replacement. Am J Orthod Dentofacial Orthop 2011; 139: 435-45. [CrossRef]

8. Mayer TM, Hawley CE, Gunsolley JC, Feldman S. The singletooth implant: a viable alternative for single-tooth replacement. J Periodontol 2002; 73: 687-93. [CrossRef]

9. Weng D, Jacobson Z, Tarnow D, et al. H€urzeler MB, Faehn O, Sanavi F, et al. A prospective multicenter clinical trial of $3 \mathrm{i}$ machined surface implants: results after 6 years of follow-up. Int J Oral Maxillofac Implants 2003; 18: 417-23.

10. Priest G. Single-tooth implants and their role in preserving remaining teeth: A 10-year survival study. Int J Oral Maxillofac Implants 1999; 14: 181-8. 